\title{
The Microtubule-Associated Protein Doublecortin- Like Regulates the Transport of the Glucocorticoid Receptor in Neuronal Progenitor Cells
}

\author{
Carlos P. Fitzsimons, Suaad Ahmed, Christiaan F. W. Wittevrongel, Theo G. Schouten, \\ Thomas F. Dijkmans, Wim J. J. M. Scheenen, Marcel J. M. Schaaf, E. Ronald de Kloet, and \\ Erno Vreugdenhil \\ Leiden/Amsterdam Center for Drug Research (C.P.F., S.A., C.F.W.W., T.G.S., T.F.D., R.d.K., E.V.), \\ Medical Pharmacology Department, and Institute for Biology (M.J.M.S.), Clusius Laboratory, Leiden \\ University, 2300 RA Leiden, The Netherlands; and Department of Cellular Animal Physiology \\ (W.J.J.M.S.), Radboud University Nijmegen, 6500HP Nijmegen, The Netherlands
}

In neuronal cells, activated glucocorticoid receptor (GR) translocates to the nucleus guided by the cytoskeleton. However, the detailed mechanisms underlying GR translocation remain unclear. Using gain and loss of function studies, we report here for the first time that the microtubule-associated protein doublecortin-like (DCL) controls GR translocation to the nucleus. DCL overexpression in COS-1 cells, neuroblastoma cells, and rat hippocampus organotypic slice cultures impaired GR translocation and decreased GR-dependent transcriptional activity, measured by a specific reporter gene assay, in COS-1 cells. Moreover, DCL and GR directly interact on microtubule bundles formed by DCL overexpression. A C-terminal truncated DCL with conserved microtubule-bundling activity did not influence GR translocation. In N1E115 mouse neuroblastoma cells and neuronal progenitor cells in rat hippocampus organotypic slice cultures, laser-scanning confocal microscopy showed colabeling of endogenously expressed DCL and GR. In these systems, RNA-interferencemediated DCL knockdown hampered GR translocation. Thus, we conclude that DCL expression is tightly regulated to adequately control GR transport. Because DCL is primarily expressed in neuronal progenitor cells, our results introduce this microtubule-associated protein as a new modulator of GR signaling in this cell type and suggest the existence of cell-specific mechanisms regulating GR translocation to the nucleus. (Molecular Endocrinology 22: 248-262, 2008)
N THE HIPPOCAMPUS, adrenal corticosteroids exert profound effects on neurogenesis, cognitive processes, and adaptation to stress. These actions are mediated by two related receptor molecules, the mineralocorticoid receptor and the glucocorticoid receptor (GR) (1). In the cytosol, the GR is part of a protein heterocomplex designated transportosome, consisting of chaperone proteins such as heat shock protein 90 (hsp90) (2), immunophilins, and dynein (3). Upon glucocorticoid (GC) binding, the transportosome complex remodels and translocates the activated GR to the nucleus using microtubule tracks (4). However,

First Published Online November 1, 2007

Abbreviations: CAM, Calmodulin; DCL, doublecortin-like; DCX, doublecortin; DEX, dexamethasone; DIV5, day in vitro 5; DMSO, dimethylsulfoxide; EGFP, enhanced green fluorescent protein; EYFP, enhanced yellow fluorescent protein; FRET, Förster resonance energy transfer; GC, glucocorticoid; GFAP, glial fibrillary acidic protein; GR, glucocorticoid receptor; hsp90, heat shock protein 90; JNK, c-Jun N-terminal kinase; LV, lentiviral vector; MAP, microtubule-associated protein; NPC, neuronal progenitor cell; OTS, organotypic slice; YFP-GR, yellow fluorescent protein-tagged GR.

Molecular Endocrinology is published monthly by The Endocrine Society (http://www.endo-society.org), the foremost professional society serving the endocrine community. beyond the involvement of heat shock proteins, immunophilins, and dynein, little is know about cell typespecific factors regulating GR translocation. In the hippocampus, quiescent neuronal progenitor cells (NPCs) are GR positive (5). Exposure of these NPCs to the GR agonist dexamethasone (DEX) inhibits their proliferation (6). However, how GR signaling is regulated in NPCs is not yet completely understood.

Doublecortin-like (DCL), a splice variant of the DCLK gene, is expressed in NPCs with high specificity (7-9). Products of the DCLK gene are involved in mitotic spindle formation, accurate cell cycle progression, and stability of cellular processes in NPCs $(8,9)$. Moreover, DCLK may regulate microtubule-based vesicle transport (10), and in vitro data have shown direct protein-protein interaction between dynein and products of the DCLK gene (8). DCL is a microtubuleassociated protein (MAP) that exhibits high sequence identity with doublecortin (DCX), which plays a crucial role in neuronal migration by interacting with tubulin and other proteins, including dynein $(9,11)$. Exogenous DCL overexpression in cell lines induces a marked microtubule bundling $(8,9)$.

Based on previous evidence demonstrating that GR translocates to the nucleus on microtubule tracks in a dynein-dependent manner (12), we speculated that 
DCL is involved in GR translocation to the nucleus. To test this hypothesis, we over-expressed DCL with a previously characterized $\mathrm{N}$-terminal yellow fluorescent protein-tagged GR (YFP-GR) (13) in COS-1 cells and in neuroblastoma cells and NPCs in rat hippocampus organotypic slice (OTS) cultures, both endogenously expressing GR. Similar systems have been extensively used to study GR translocation to the nucleus $(14,15)$. In addition, we used short hairpin RNA-mediated RNA interference to down-regulate DCL expression in N1E115 mouse neuroblastoma cells and in OTS cultures from early postnatal rat hippocampus. Our results reveal a function for DCL in GR translocation to the nucleus and therefore, for the first time, provide evidence supporting the involvement of cell type-specific MAPs, particularly from the doublecortin domain-containing family, in regulation of GR signaling.

\section{RESULTS}

\section{Overexpression Impairs GR Translocation to the Nucleus in COS-1 Cells}

To study DCL interaction with GR, YFP-GR was cotransfected with DCL in COS-1 cells. As neither GR (13) nor DCL (9) is endogenously expressed in COS-1 cells, they provide an excellent system with which to study DCL-GR interactions. Cells were cotransfected with YFP-GR and the empty pcDNA 3.1 vector as experimental control. Transfected cells were exposed to $1 \times 10^{-7} \mathrm{M}$ DEX or the GR antagonist RU486, both known to induce nuclear translocation of the receptor (16).

Observation of pcDNA 3.1-DCL and YFP-GR coexpressing cells showed a clear retention of YFP-GR on the microtubule bundles induced by $D C L$ expression, as compared with control cells (Fig. 1, A and B). DEX and RU486 induced YFP-GR translocation to the nucleus with a calculated $t_{1 / 2}$ of $10.7 \pm 1.5 \mathrm{~min}$ and $8.7 \pm$ $0.5 \mathrm{~min}$, respectively at $37 \mathrm{C}$ (Fig. $1 \mathrm{C}$ ). This effect was readily observed as soon as 10 min after DEX treatment (Fig. 1C). A complete YFP-GR translocation was reached after $30 \mathrm{~min}$ and lasted for at least $1 \mathrm{~h}$ in the presence of the ligand in control cells (Fig. 1C). Coexpression of pcDNA 3.1-DCL induced a significant decrease in the maximal amount of ligand-induced YFP-GR translocation to the nucleus $30 \mathrm{~min}$ after ligand application $(41.3 \pm 5.4 \%$ and $43.6 \pm 3.1 \%$ decrease, DEX and RU486, respectively; $\mathrm{n}=3, P<0.05$ ) (Fig. 1C). The half-lives of the translocated fractions induced by DEX and RU486 were not significantly different from those observed in control cells (10.99 \pm $2.8 \mathrm{~min}$ DEX, $10.32 \pm 1.7 \mathrm{RU} 486$ vs. and $8.75 \pm 3.2 \mathrm{~min}$ DEX, 7.78 土 3.8 RU486, respectively; $n=3$ ) (Fig. 1C).

Consistent with these observations, coexpression of pcDNA 3.1-DCL with YFP-GR induced a significant reduction in the maximal GR-dependent transcriptional activity induced by DEX treatment $(38.25 \pm$ $3.5 \%$ decrease; $n=3, P<0.05$ ), without affecting its
$\mathrm{pEC}_{50}$ value $(8.3 \pm 0.3$ vs. $8.6 \pm 0.2$, with and without pcDNA 3.1-DCL, respectively; $n=3$ ) as measured by a dual luciferase GR-reporter gene assay (Fig. 1D). This last observation suggests that the presence of DCL did not affect GR binding affinity for DEX. DEXinduced GR-dependent transcriptional activity was specifically blocked by incubation with $1 \times 10^{-7} \mathrm{M}$ RU486, whereas vehicle-treated cells showed no effect (data not shown).

These results were confirmed by cotransfection of YFP-GR with a DCL C-terminal fusion protein to the red fluorescent protein DsRed2 (DCL-DsRed2) and time-lapse confocal microscopy on live cells, showing a clear retention of YFP-GR on the DCL-DsRed2-induced microtubule bundles after $1 \times 10^{-7} \mathrm{M}$ DEX application (supplemental video 1 published as supplemental data on The Endocrine Society's Journals Online web site at http://mend.endojournals.org).

Interestingly, in a significant proportion of cells expressing DCL, YFP-GR formed globular hotspots of protein accumulation on the microtubule bundles after DEX treatment (Fig. 1B). Laser scanning confocal microscopy showed that DCL-DsRed2 and YFP-GR were colocalized on microtubule bundles formed by DCL in vehicle-treated cells (Fig. 2A). The hotspots of protein accumulation induced by DEX treatment (30 min, $1 \times 10^{-7} \mathrm{M}$ ) displayed a high degree of YFP-GR colocalization with DCL-DsRed2 (Fig. 2B). Formation of similar globular accumulations on microtubule tracks containing activated GR has been previously described associated with treatment with the hsp90 inhibitor geldanamycin (17).

The C-terminal serine/proline-rich domain of DCX, which shares high amino acid identity with DCL (9), is involved in protein-protein interactions (18). Consistent with this idea we mapped the DCL domain involved in regulating $\mathrm{GR}$ translocation to the $\mathrm{C}$-terminal serine/proline-rich domain of DCL. Cotransfection of COS-1 cells with YFP-GR and a DsRed2-tagged Cterminal truncation of $\mathrm{DCL}$, lacking the complete serine/proline-rich domain (T285DCL-DsRed2), induced microtubule bundling similar to full-length $\mathrm{DCL}$ but had no effect on YFP-GR translocation to the nucleus (Fig. 2, C and D).

Taken together, these results suggest that expression of DCL in COS-1 cells induced obstructions on microtubule tracks that interfere with GR transport to the nucleus.

To test for the specificity of these observations, we performed a number of experimental controls (supplemental Fig. 1). These experiments demonstrated that: 1) the effect of DCL on YFP-GR translocation could not be explained simply by a physical hindrance induced by microtubule bundling; 2) DCL expression does not interfere with GR coupling to hsp90; 3) the effects of DCL on YFP-GR translocation are not a consequence of a general cytoskeleton disarrangement. Therefore, the effects of DCL on GR translocation seem to be the result of a specific mechanism, most likely involving protein-protein interactions 
A
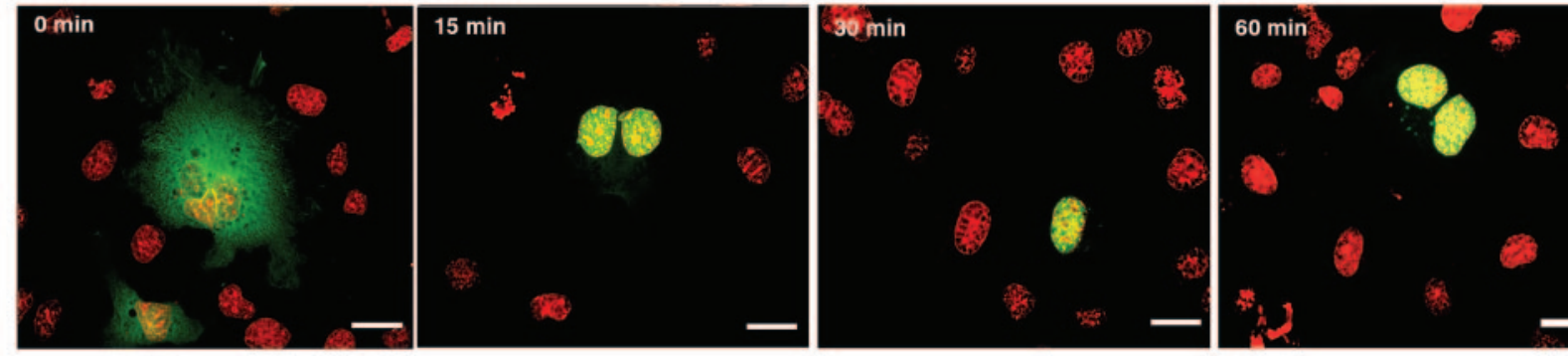

B
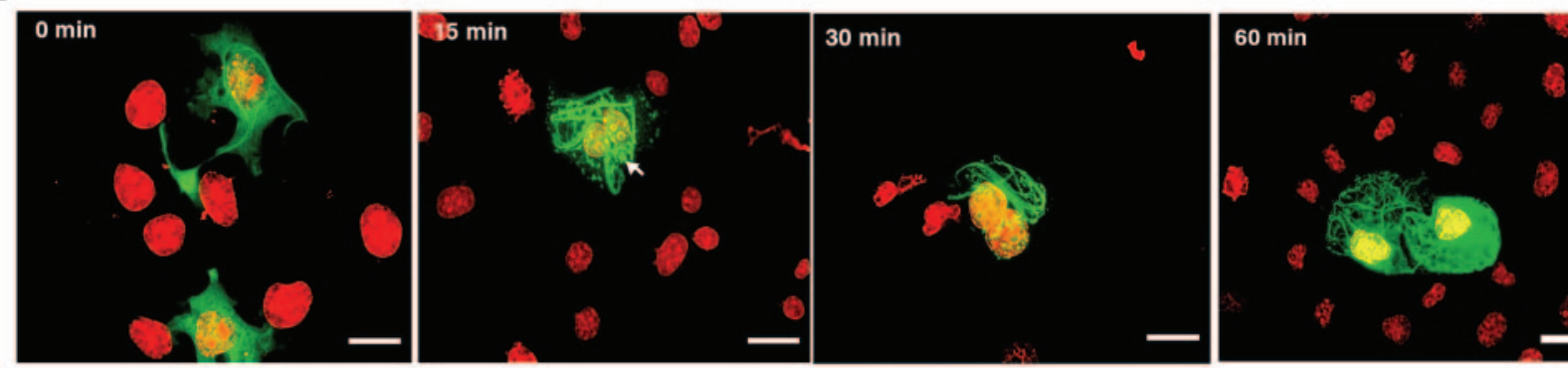

C

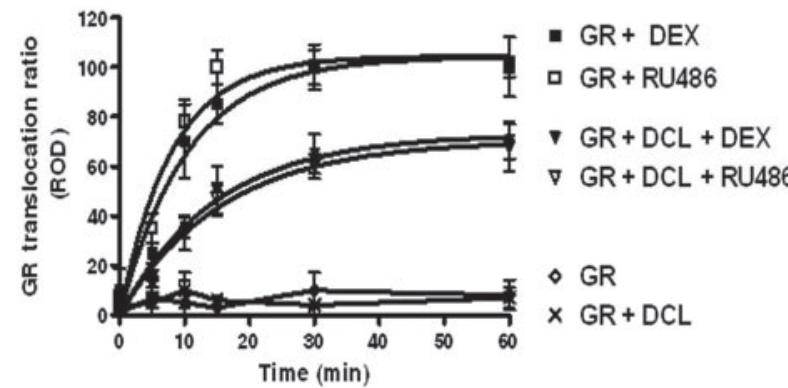

D

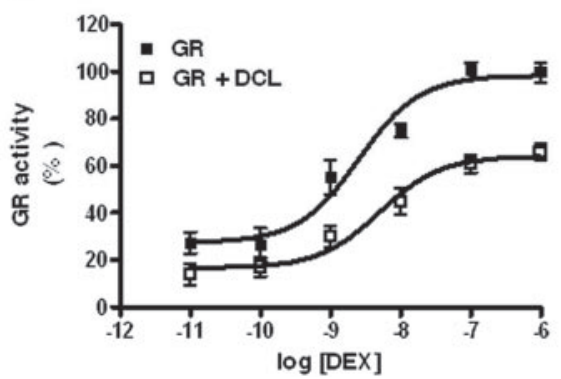

Fig. 1. DCL Expression Impairs GR Translocation to the Nucleus in COS-1 Cells

Time frame of GR translocation in the absence (A) or presence (B) of pcDNA 3.1-DCL (DCL). YFP-GR (green) and Hoechst 33342 (red). Scale bar, $32 \mu \mathrm{m}$. Arrow indicates GR accumulations after DEX treatment on microtubule bundles induced by DCL. C, Time frame of GR translocation induced by DEX and RU486 in the presence or absence of DCL. Results are expressed as nucleus-cytosol translocation ratios and represent mean \pm SEM of three independent experiments (100 cells scored in each). ROD, Relative OD. D, DEX-induced GR-dependent transcriptional activity in the presence or absence of DCL, normalized to the maximal response detected in the absence of DCL.

through the C-terminal serine/proline-rich domain of DCL.

To further characterize DCL interaction with the GR, we performed biochemical assays to study protein interaction. HeLa cells, which endogenously express the GR but not DCL (Fig. 3A), were transfected with pcDNA3.1-DCL. GR and DCL coimmunoprecipitated from transfected cells when the specific GR antibody was used (Fig. 3B).

Next, we studied the intracellular location of the observed GR-DCL interaction by Förster resonance energy transfer (FRET) followed by pixel-by-pixel analysis of the FRET images using EGFP/EYFP as donor/ acceptor pair (see Materials and Methods and supplemental Fig. 2). Previous to FRET experiments, YFP-GR and EGFP-DCL were cotransfected in COS-1 cells and controlled by Western blot (Fig. 3C). As shown in Fig. 2A, EGFP-DCL expression induced microtubule bundling and a marked GR localization on these bundles, demonstrating that colocalization is independent of the nature or the location of the fluorescent tags. Quantification revealed a significant increase in FRET intensity in YFP-GR/EGFP-DCL cotransfected cells, as compared with YFP-GR/empty pEGFP-C1 vector cotransfected control cells (Fig. 3D). A detailed analysis of the FRET images revealed that the specific interaction between EYFP-GR and EGFP-DCL takes place mainly on the microtubule bundles induced by DCL expression (Fig. 3, E and F). Moreover, EGFP alone neither affected localization of YFP-GR nor interacted with YFP-GR (Fig. 3F).

\section{Overexpression Impairs GR Translocation in N1E-115 Neuroblastoma Cells}

To verify that the observed effects of DCL expression on GR translocation are not due to other factors expressed in COS-1 cells, we used the N1E-115 mouse 

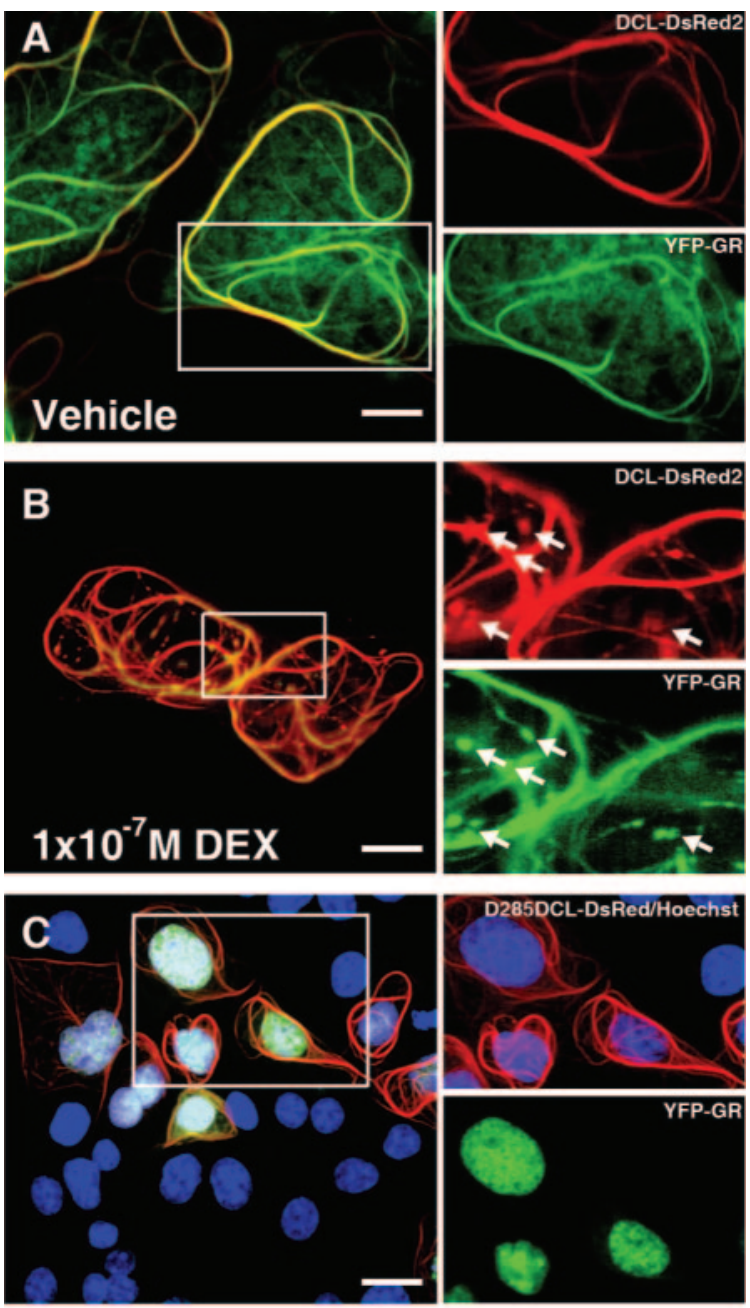

D

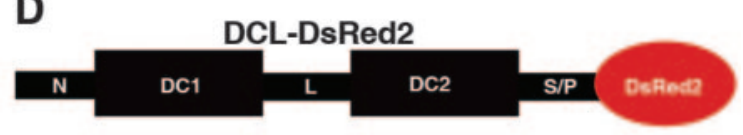

T285DCL-DsRed2

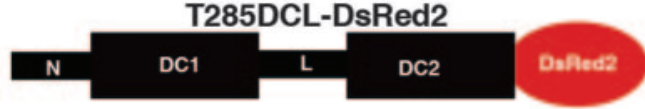

Fig. 2. YFP-GR Retention on Microtubule Bundles Is Dependent on the Presence of DCL C-Terminal Serine/Proline-Rich Domain

Colocalization of YFP-GR (green) and DsRed2-DCL (red) on microtubule bundles formed by DCL in vehicle-treated (A) and DEX-treated (B) COS-1 cells. Arrows indicate protein accumulation containing GR and DCL. C, YFP-GR (green) translocation to the nucleus (Hoechst 33342, blue) in the presence of C-terminal truncated DCL (red). D, Schematic representation of DCL-DsRed2 and its T285 truncated form. Scale bars, $20 \mu \mathrm{m}$ in A and B; $32 \mu \mathrm{m}$ in C. In all cases, one representative confocal plane is shown. S/P, Serine/prolinerich domain.

neuroblastoma cell line, which endogenously expresses GR and DCL (9, 19 ). We used dimethylsulfoxide (DMSO)-differentiated N1E-115 cells (20), the long neurites of which facilitated visualization and per- mitted study of the role of DCL in GR transport to the nucleus.

The GR transportosome includes, among other proteins, cytoplasmatic dynein, the motor protein responsible for its retrograde transport to the nucleus (12). Therefore, we used laser-scanning confocal microscopy analysis of DMSO-treated N1E-115 cells to study possible DCL, GR, and dynein colocalization. As previously shown (9) we found native DCL largely colocalized with tubulin and strongly present and distributed along neurites of differentiated cells, suggesting a function in these structures (Fig. 4A). In neurites, DCL colocalized with GR (Fig. 4B) and dynein intermediate chain (Fig. 4C).

DCL-DsRed2 overexpression resulted in a cellular phenotype characterized by microtubule bundling, cell flattening, and changes in cells morphology (Fig. 4, $\mathrm{D}-\mathrm{G})$. The endogenous GR accumulated on the microtubule bundles induced by DCL overexpression. Treatment of the cells with $1 \times 10^{-7} \mathrm{M} \operatorname{DEX}(30 \mathrm{~min})$ did not result in visible changes in GR localization, with GR still strongly colocalized to DCL on microtubule bundles, as compared with vehicle-treated cells (Fig. 4, D and E).

Conversely, in control cells transfected with empty DsRed2 (pDsRed2-N1 vector), treatment with $1 \times$ $10^{-7}$ M DEX (30 min) resulted in GR depletion form neurites and accumulation in the nuclear and perinuclear area (Fig. 4, F and G).

\section{Knockdown Affects GR Translocation in N1E-115 Neuroblastoma Cells}

Next, we studied the effect of DCL knockdown on GR translocation in N1E-115 cells, a system with native stoichiometry. We used pS-DCL, a previously described pSUPER-based plasmid encoding a perfect match short hairpin RNA against DCL, and its mismatched control pS-DCLm for successive experiments (9).

pS-DCL down-regulated, in a dose-dependent manner, the expression of endogenous DCL at the mRNA level as measured by qPCR (Fig. 5A) and the protein level as measured by Western blot (Fig. 5B). This dose dependency suggested that increasing the expression levels of DCL could counteract the effects of pS-DCL. Effectively, overexpression of DCLDsRed2 $\left(1 \mu \mathrm{g} / 1 \times 10^{-6}\right.$ cells) restored, albeit only partially, DCL expression levels (Fig. 5B). pS-DCLm did not have significant effects on DCL expression (Fig. 5, A and B). pS-DCL did not influence the expression of $\alpha$-tubulin (Fig. 5B) or $\beta$-actin (data not shown), suggesting that its effects were specific for DCL.

For GR translocation studies, cells were cotransfected with pEBFP-C1 as transfection control (data not shown) and pS-DCL or pS-DCLm (1:5). Cells were exposed, $24 \mathrm{~h}$ after transfection, to $2 \%$ DMSO for $5 \mathrm{~d}$. On the fourth day medium was changed to culture medium containing $2 \%$ charcoal-activated stripped fetal bovine serum and $2 \%$ DMSO. On the fifth day 


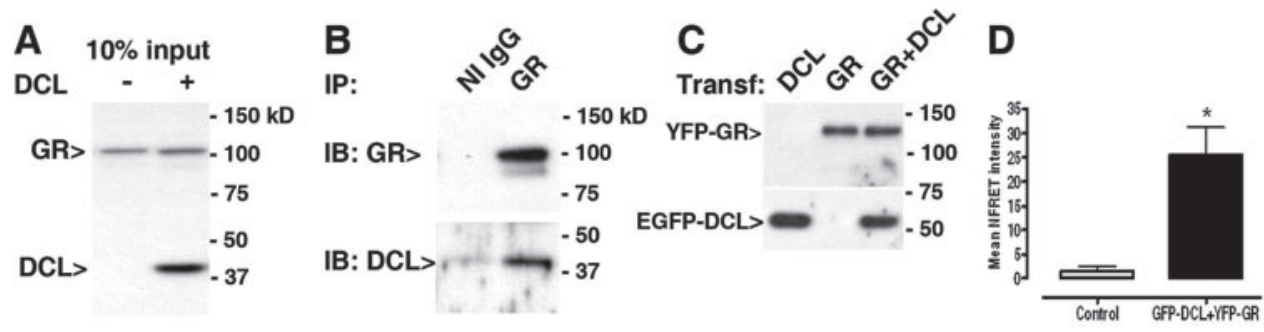

$\mathbf{E}$
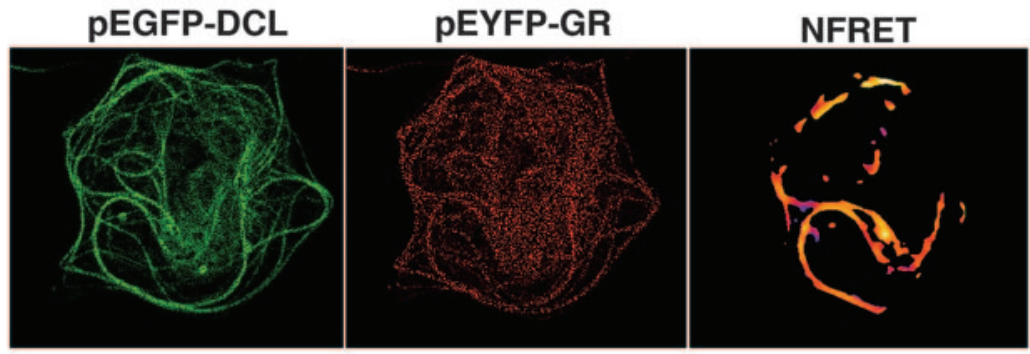

$\mathbf{F}$
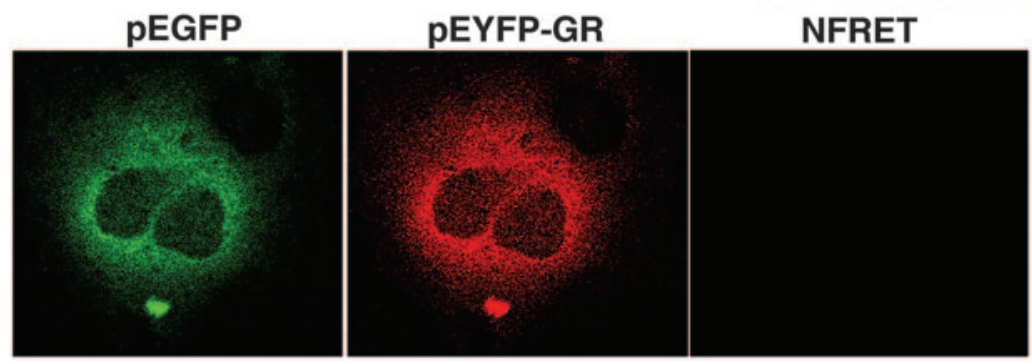

Fig. 3. DCL Directly Interacts with GR

Coimmunoprecipation of GR and DCL from transfected (A) Hela cells, endogenously express GR but not DCL (10\% of the input used in B). B, Western blot detection of GR and DCL after immunoprecipitation with GR antibody from lysates of transfected Hela cells. NI IgG, Rabbit nonimmune IgG. C, COS-1 cells transfected with YFP-GR, EGFP-DCL, or both previous to FRET experiments. In all cases figures show a representative gel of four run independently. D, Mean normalized FRET intensities (NFRET) from cells cotransfected with EGFP-DCL and YFP-GR (black bar) or with pEGFP-C1 and YFP-GR (white bar). Results represent mean \pm SEM of 36 cells each, from three independent experiments. *, Significantly different. Linearly unmixed cell images and the corresponding pseudo-colored NFRET image to improve visualization, showing highest NFRET intensities on microtubule bundles in cells coexpressing EGFP-DCL and YFP-GR (panel E) or undetectable NFRET in cells coexpressing EGFP and YFP-GR (panel F). Color bar represents NFRET intensity scale. IB, Immunoblotting; IP, immunoprecipitation; Transf., transfection.

cells were exposed to $1 \times 10^{-7}$ DEX or vehicle for 30 min at $37 \mathrm{C}$ and immediately fixed.

Laser-scanning confocal microscopy demonstrated a large amount of GR still retained in neurites of pSDCL transfected cells after DEX incubation (Fig. 5C). In comparison, upon DEX treatment GR was significantly depleted from neurites and accumulated in the nucleus and perinuclear area in pS-DCLm-transfected cells (Fig. 5D). Neurites seemed structurally not affected by DCL down-regulation as revealed by $\alpha$-tubulin staining (Fig. 5, C and D).

In pS-DCL transfected cells, after DEX treatment colocalization of GR to tubulin in neurites was significantly higher than in pS-DCLm-transfected cells (Fig. $5 \mathrm{E}$, colocalization scores $0.55 \pm 0.09$ vs. $0.08 \pm 0.06$, respectively; $P<0.05,100$ cells) or mock (pSuper) transfected cells (Fig. 5E, colocalization scores $0.55 \pm$ 0.09 vs. $0.05 \pm 0.05$, respectively; $P<0.05,100$ cells).
Similarly, DEX-induced GR translocation to the nucleus was significantly reduced as compared with cells transfected with pS-DCLm $(73.4 \pm 18.6 \% ; 100$ cells per condition; $P<0.05$; Fig. $5 \mathrm{~F}$ ). The transcriptional activity of the endogenous GR was increased in a dose-dependent manner by DEX $\left(\mathrm{pEC}_{50}=8.01 \pm\right.$ $0.73 ; n=4)$, as measured by a specific GR reporter gene assay. This DEX-induced increase in GR transcriptional activity was dose-dependently blocked in a dose-dependent manner by RU486 $\left(\mathrm{pEC}_{50}=8.20 \pm\right.$ $0.36 ; n=4$ ), providing a pharmacologically well-characterized system with which to study GR-dependent transcriptional activity. Transfection with pS-DCL significantly decreased DEX-stimulated GR-dependent transcriptional activity as compared with pS-DCLm-transfected cells (53.9 $\pm 7.72 \% ; n=3 ; P<0.05$; Fig. 5G).

Mitochondria labeled with MitoTracker Red CMXR (Invitrogen BV, Breda, The Netherlands) were evenly 

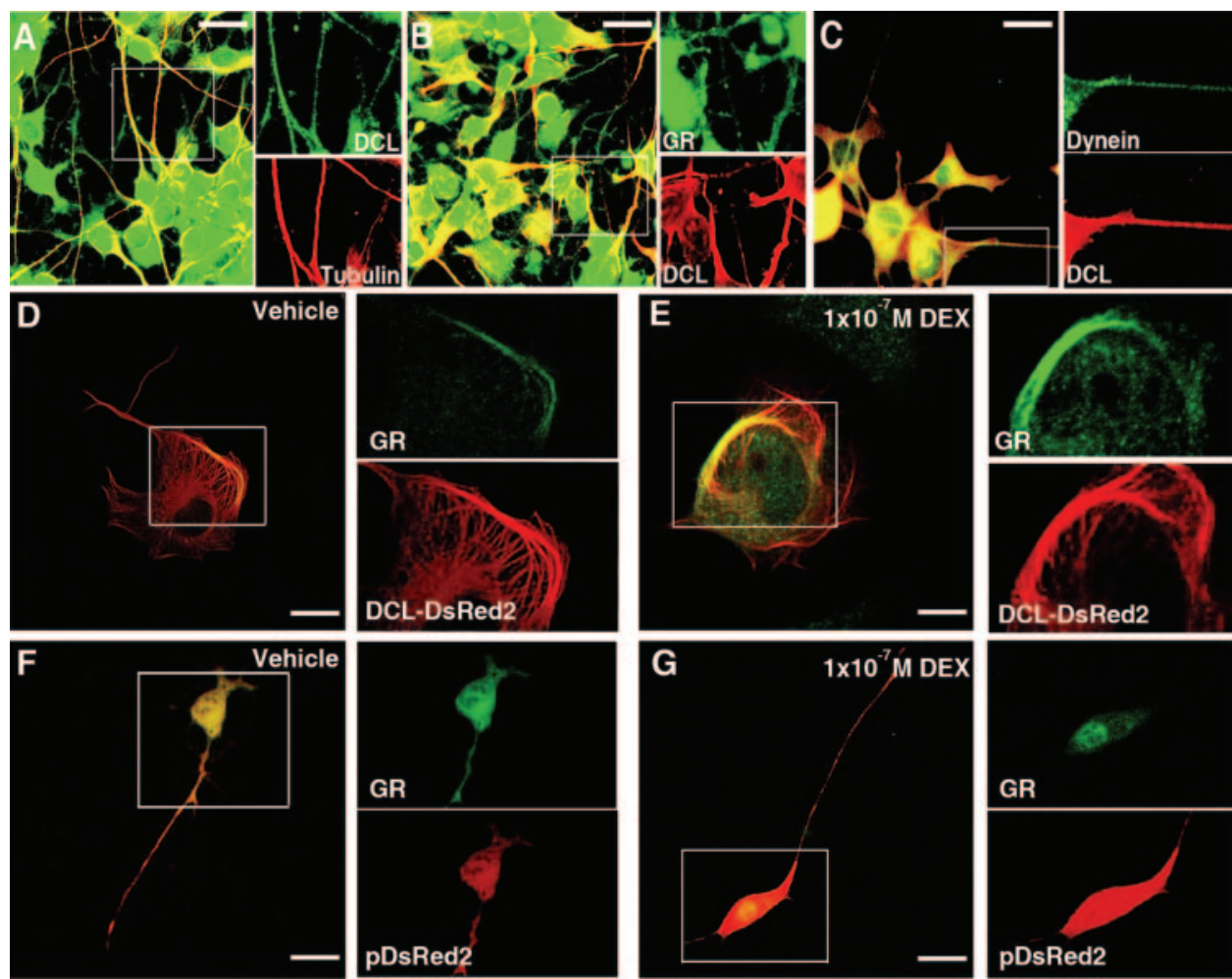

Fig. 4. DCL Overexpression Impairs GR Translocation in N1E-115 Cells

Colocalization of endogenous: DCL (green) and tubulin (red) (A); GR (green) and DCL (red) (B); and dynein (green) and DCL (red) (C) in neurites and soma of DMSO-differentiated cells. Vehicle (D) or DEX-induced (E) GR (green) translocation in cells transfected with DCL-DsRed2 (red). GR/tubulin colocalization scores were: $0.42 \pm 0.9$ vs. $0.37 \pm 0.7$, vehicle and DEX-treated cells, respectively (mean \pm SEM of 72 cells scored in three independent experiments each). Vehicle (F) or DEX-induced (G) GR (green) translocation in cells transfected with pDsRed2 (red). GR/tubulin colocalization scores were: $0.68 \pm 0.6$ vs. $0.18 \pm 0.5$, vehicle and DEX-treated cells, respectively (mean \pm SEM of 88 cells scored in three independent experiments each, significantly different). Scale bars, $20 \mu \mathrm{m}$ in $\mathrm{D}$ and $\mathrm{E} ; 32 \mu \mathrm{m}$ in $\mathrm{F}$ and $\mathrm{G}$.

distributed along neurites and present in the soma and neurite extremities in pS-DCL and in pS-DCLm-transfected N1E-115 cells (supplemental Fig. 3). These observations suggest that DCL down-regulation does not significantly influence mitochondria transport, which has been shown to be affected by other MAPs involved in microtubule-dependent transport (21).

\section{Overexpression Impairs GR Translocation in NPCs of Early Postnatal Rat Hippocampal Organotypic Slices}

DCLK is one of the most enriched MAPs in NPCs present in the developing brain (8), a cell type in which the GR controls cell proliferation (6). To study a possible role of $\mathrm{DCL}$ in $\mathrm{GR}$ transport to the nucleus in NPCs, we used OTS cultures. In the present work we focused on the hilus of the developing dentate gyrus formation, where most NPCs are localized, generating neurons that migrate to form the granular layer (22).

OTSs were transduced with the modified lentiviral vector LV-DCL-DsRed2 to induce DCL overexpression. Four days after transduction (day in vitro 5, DIV5), slices were processed and GR translocation was mea- sured in DCL-DsRed2-expressing hilar cells showing a phenotype with bundled microtubules (Fig. 6).

DCL overexpression in these cells induced a marked colocalization of GR to the microtubule bundles induced by DCL-DsRed2 expression. Interestingly, treatment with $1 \times 10^{-7} \mathrm{M}$ DEX for $30 \mathrm{~min}$ did not induce significant changes in GR localization, with GR retained on DCL-DsRed2-containing bundles (Fig. 6A), as observed in vehicle-treated cells (Fig. 6B). Conversely, in OTSs transduced with the LV-DsRed2 lentiviral vector, treatment with $1 \times 10^{-7} \mathrm{M}$ DEX for $30 \mathrm{~min}$ induced a significant decrease in GR localization to DsRed2 and accumulation in the cells soma and nuclear areas, whereas GR was diffusely expressed in vehicle-treated DsRed2-expressing cells (Fig. 6, C and D).

To further characterize these observations we quantified DCL-DsRed2 or DsRed2/GR colocalization in processes of DCL-DsRed2 ${ }^{+}$or DsRed2 cells, respectively, by using the Overlap Coefficient $\mathrm{R}$ method (see Materials and Methods).

Colocalized pixels were represented in a black and white bitmap using ImageJ (Fig. 6E). In line with our DCL overexpression data from COS-1 and N1E-115 
A

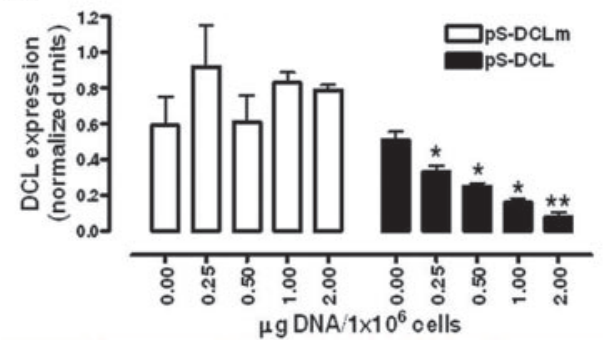

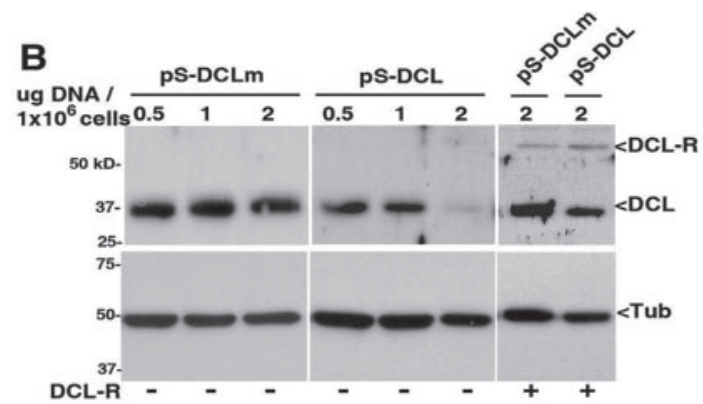

E
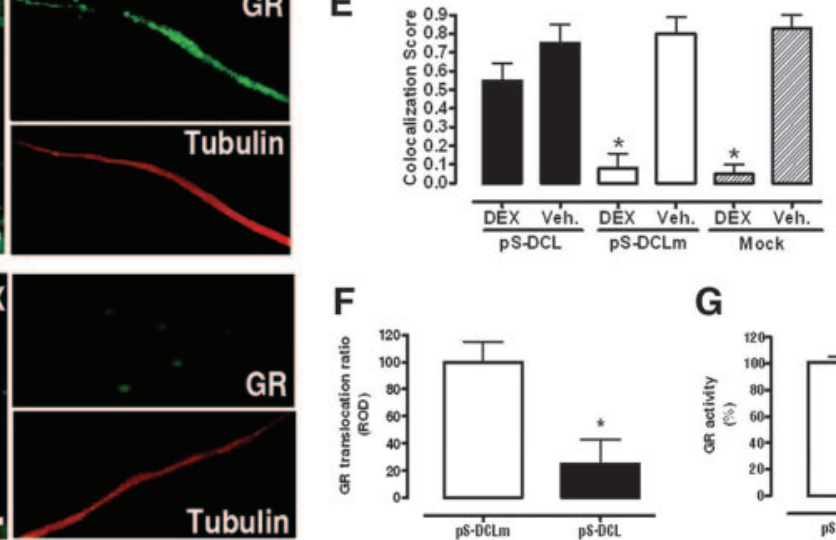

$\mathbf{F}$

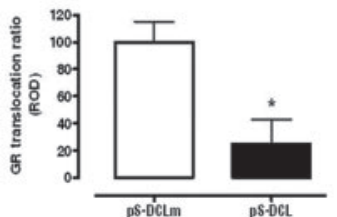

G

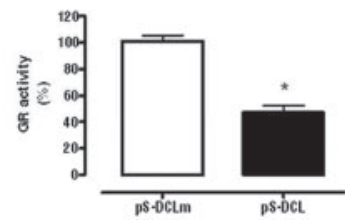

Fig. 5. DCL Down-Regulation Affects GR Translocation in N1E-115 Cells

A, Dose-dependent DCL mRNA down-regulation induced by pS-DCL, as compared with pS-DCLm. DCL levels were normalized to the $18 \mathrm{~S}$ subunit of rRNA. Results represent mean \pm SEM of three independent experiments performed in duplicate. $F$, Dose-dependent DCL protein down-regulation induced by pS-DCL as compared with pS-DCLm and recovery of DCL expression levels by cotransfection with DCL-DsRed2 (DCL-R). Results shown are from one representative experiment of three independent ones performed in duplicates. Molecular weight markers are indicated on the left. C and D, DEX-induced GR (green) translocation in neurites (tubulin, red) of pS-DCL or pS-DCLm-transfected cells. E, GR/tubulin colocalization scores after DEX treatment in cellular processes in pS-DCL or pS-DCLm-transduced cells. Neurites were selected as areas of interest for score calculations. Mock-transfected cells treated with DEX or vehicle are shown as experimental controls. *, Significantly different from mocktransfected, vehicle-treated cells (Mock Veh). F, DEX-induced nucleus-cytosol GR translocation ratios in pS-DCLm- or pS-DCLtransfected cells. (mean \pm SEM of three independent experiments; 100 cells scored in each). G, DEX-induced GR-dependent transcriptional activity in PS-DCLm- or pS-DCL-transfected cells (mean \pm SEM of three independent experiments performed in duplicates). Scale bars, 20 um. *, Significantly different. Tub., Tubulin; Veh., vehicle.

cells, we noted retention of the GR on DCL-DsRed2containing bundles after DEX treatment, as compared with vehicle-treated cells (Fig. 6F). A significantly increased colocalization score in LV-DCL-DsRed2treated slices, as compared with LV-DsRed2-treated slices was observed $(0.52 \pm 0.15$ vs. $0.1 \pm 0.12$, respectively; 43 processes counted in three independent DEX-treated slices each).

\section{Knockdown Affects GR Translocation in NPCs of Early Postnatal Rat Hippocampal Organotypic Slices}

To induce DCL knockdown, OTSs were transduced with modified lentiviral vectors to deliver DCL short hairpin RNA (LV-DCL) and its mismatch control (LVDCLm). Four days after transduction with LV-DCLm (DIV5), DCL expression was detected in $87 \pm 9 \%$ of the EGFP-positive cells phenotypically resembling quiescent NPCs in the adult subgranular zone (23).
However, in OTSs transduced with LV-DCL, $44 \pm 6 \%$ of the EGFP-positive cells were DCL negative, suggesting an effective, although partial, DCL knockdown (Fig. 7, A and B).

After incubation in culture medium containing DEX $\left(1 \times 10^{-7} \mathrm{M}, 90 \mathrm{~min}\right), \mathrm{GR}$ immunoreactivity was significantly retained in the processes of LV-DCL-transduced EGFP + cells compared with LV-DCLm-transduced cells (Fig. 7, C and D), indicating that DCL knockdown in NPCs results in impairment of DEXstimulated GR translocation. Control LV-DCLm-transduced cells, treated with vehicle in otherwise identical experimental conditions, showed GR abundantly present in cellular processes of EGFP+ cells, discarding a nonspecific induction of GR transport to the nucleus by transduction with LV-DCLm (Fig. 7D).

EGFP/GR colocalization analyses in processes of EGFP + cells revealed retention of the GR on cellular processes after DEX treatment (Fig. 7, E and F), ob- 

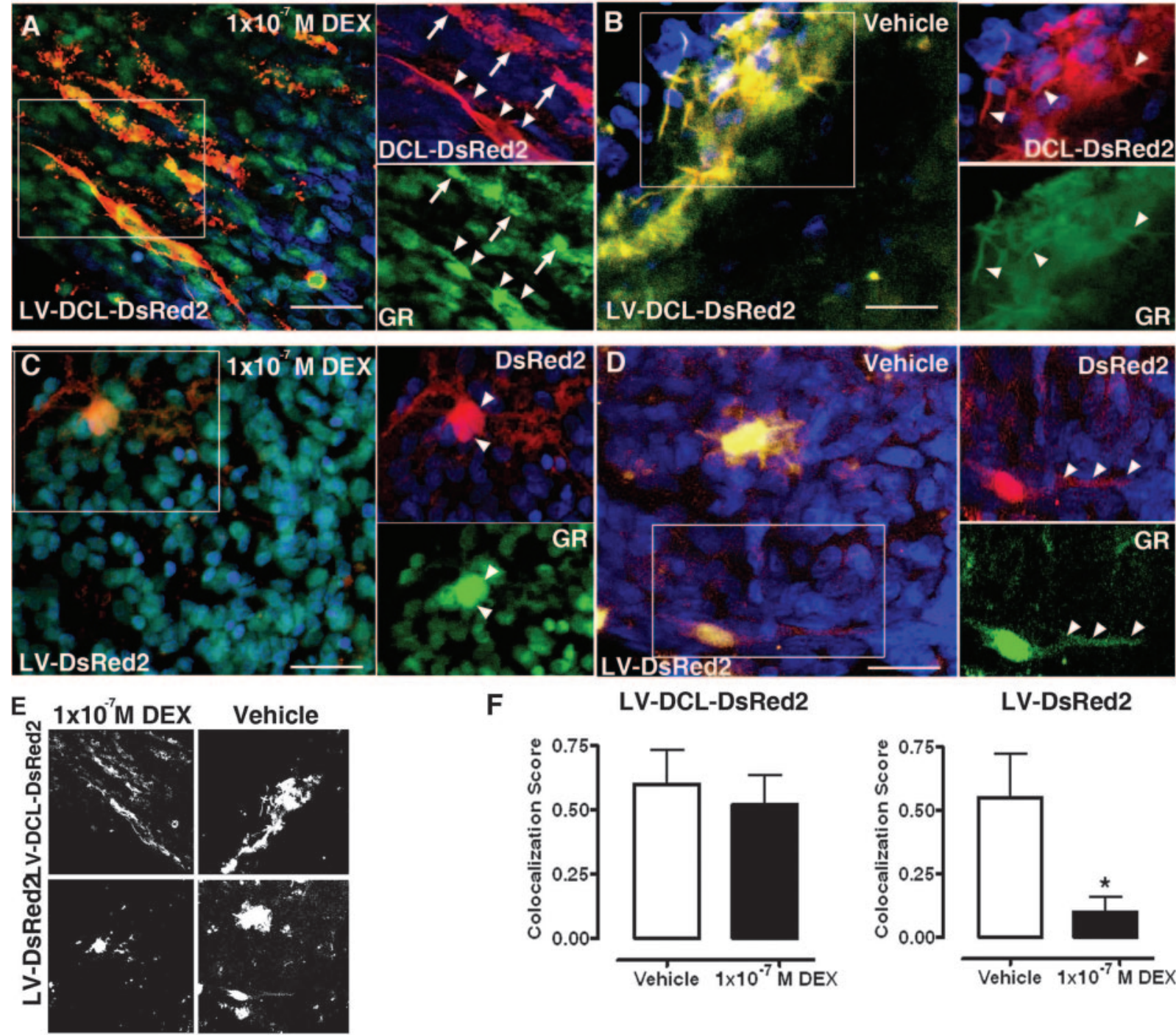

$\mathbf{F}$

LV-DCL-DsRed2

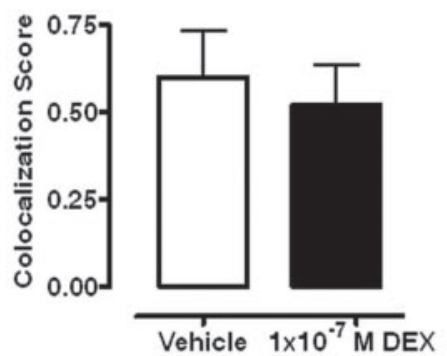

LV-DsRed2

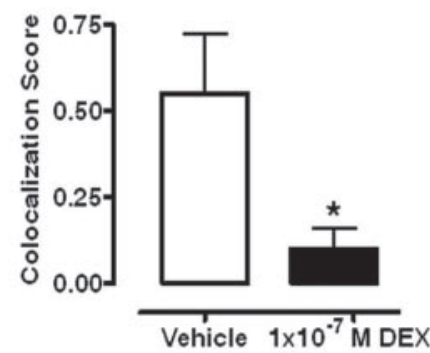

Fig. 6. DCL Overexpression Impairs GR Translocation in Rat Hippocampal Organotypic Slice Cultures

DEX- (A) or vehicle-induced (B) GR (green) translocation in DCL-DsRed2 (red)-expressing cells in LV-DCL-DsRed2-transduced slices. Insets, GR/DCL colocalization on structures resembling microtubule bundles (arrowheads) or hotspots of protein accumulation (arrows) observed in COS-1 cells (Fig. 2). DEX- (C) or vehicle-induced (D) GR (green) translocation in DsRed2 $(r e d)$-expressing cells in LV-DsRed2-transduced slices. Insets, arrowheads indicate GR/DCL colocalization spots in nuclear/ perinuclear areas (C) or cellular processes (D). E, Grayscale bitmaps from A and B (top) or C and D (bottom) showing GR/EGFP-colocalized pixels. F, GR/DsRed2 colocalization scores in cellular processes in LV-DCL-DsRed2 or LV-DsRedtransduced slices treated with vehicle or DEX. Cellular processes were selected as areas of interest for score calculations. *, Significantly different. Scale bars, $20 \mu \mathrm{m}$.

served as a significant increase in colocalization score in LV-DCL-treated slices, as compared with LVDCLm-treated ones $(0.42 \pm 0.09$ vs. $0.1 \pm 0.07$, respectively; 56 processes counted in three independent DEX-treated slices each).

For neural progenitor characterization and morphology, we used markers proposed for the adult hippocampus (23). According to this classification, we focused our studies on cells with nestin +/glial fibrillary acidic protein (GFAP) + processes present in the early postnatal hilus (Fig. 8A). Staining with a DCL antibody revealed a large extent of colabeling with nestin (Fig. 8B) and, to a lesser extent, with GFAP (Fig. 8C). A large proportion of the nestin-positive processes showed colocalization with DCL $(74 \pm 7 \%$ of a total 266 processes counted in three independent slices) (Fig. 8, B and D). A significantly smaller proportion of the GFAP+ processes showed colocalization with DCL $(26 \pm 9 \%$, of a total 248 processes counted in three independent slices) (Fig. 8, C and D). These results indicated that DCL is expressed in most nestin+/GFAP + NPCs, which represented $44 \pm$ $8 \%$ of the nestin-positive cellular processes of a total of 210 counted in three independent OTS cultures (Fig. 8, A and D). 

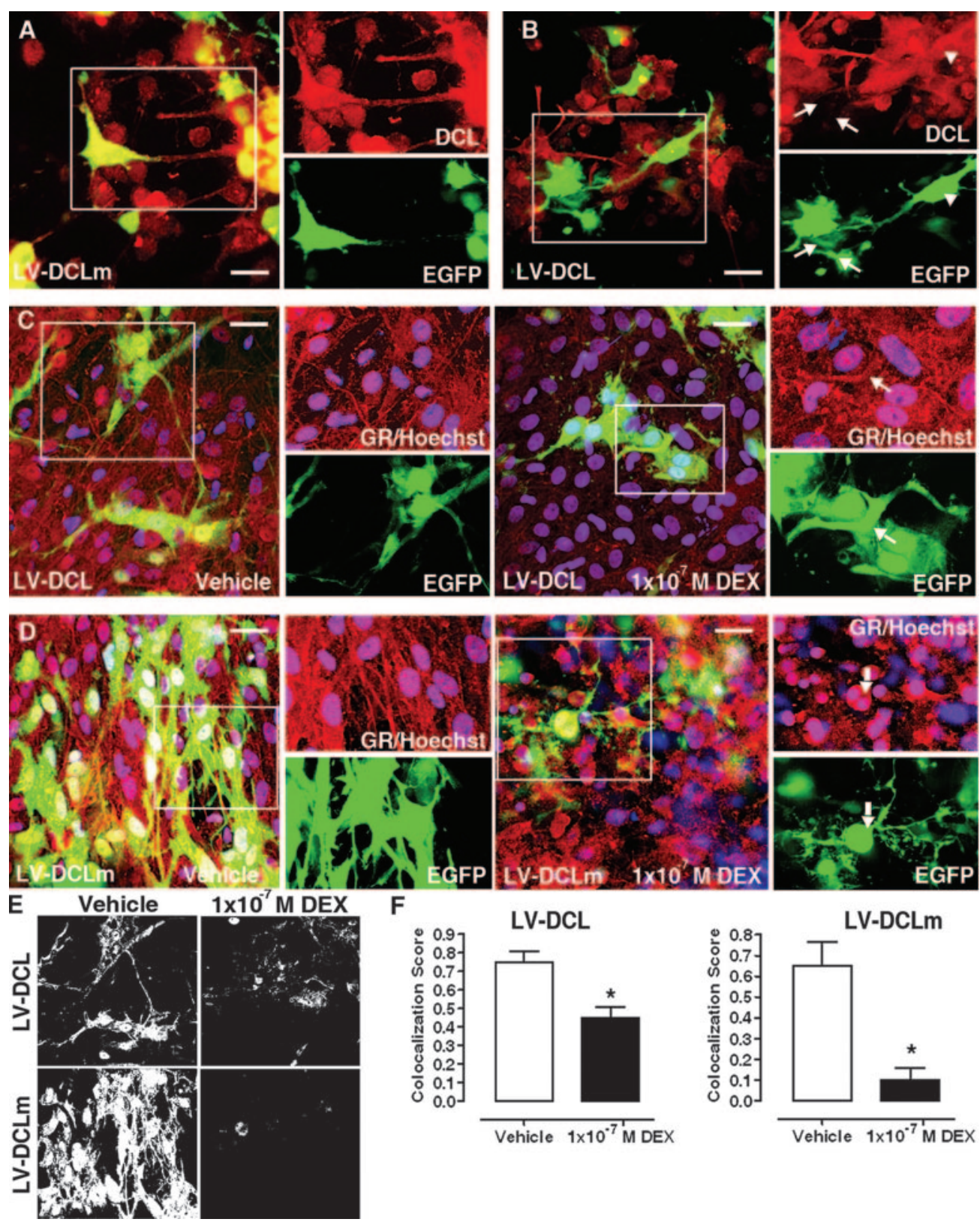

Fig. 7. DCL Down-Regulation Affects GR Translocation in Rat Hippocampal Organotypic Slice Cultures

A, DCL (red) expression in LV-DCLm (EGFP, green)-transduced slices. B, DCL (red) expression in LV-DCL (EGFP, green)transduced slices. Inset, a group of EGFP-positive cells with complete (arrow) or partial (arrowhead) knockdown and their different phenotype. C, DEX insensitivity in LV-DCL-transduced slices. Inset, GR (red) retention in processes of EGFP-positive (green) cells (arrow). D, DEX-induced GR translocation in LV-DCLm-transduced slices. Inset, Nuclear accumulation of GR (red) in EGFPpositive (green) cells (arrow). Nuclei are stained in blue (Hoechst); vehicle-treated cells are shown as negative control on left panels. E, Grayscale bitmaps from panels C (top) and D (bottom) showing GR/EGFP colocalized pixels. F, GR/EGFP colocalization scores in cellular processes in LV-DCL- or LV-DCLm-transduced slices. Cellular processes were selected as areas of interest for score calculations. * $P<0.05$. Scale bars, $20 \mu \mathrm{m}$.

To determine whether DCL was the main DCLK isoform expressed in NPCs, we stained with a CPG16 antibody, recognizing calmodulin (CAM) kinase homology domain-containing DCLK isoforms.

Laser-scanning confocal microscopy of DCL-positive cells in the hilus of the dentate gyrus (DIV5) revealed no colocalization with the weak nuclear CPG16 signal de- tected in NPCs (Fig. 8E), whereas the CPG16 antibody specifically labeled NeuN-positive cells in DIV21 OTSs (data not shown). These observations confirmed that CAM kinase homology domain-containing DCLK isoforms are mainly not expressed in NPCs $(24,25)$. In line with published data, Nestin+/GFAP+ NPCs were also negative for DCX (data not shown) (23). 

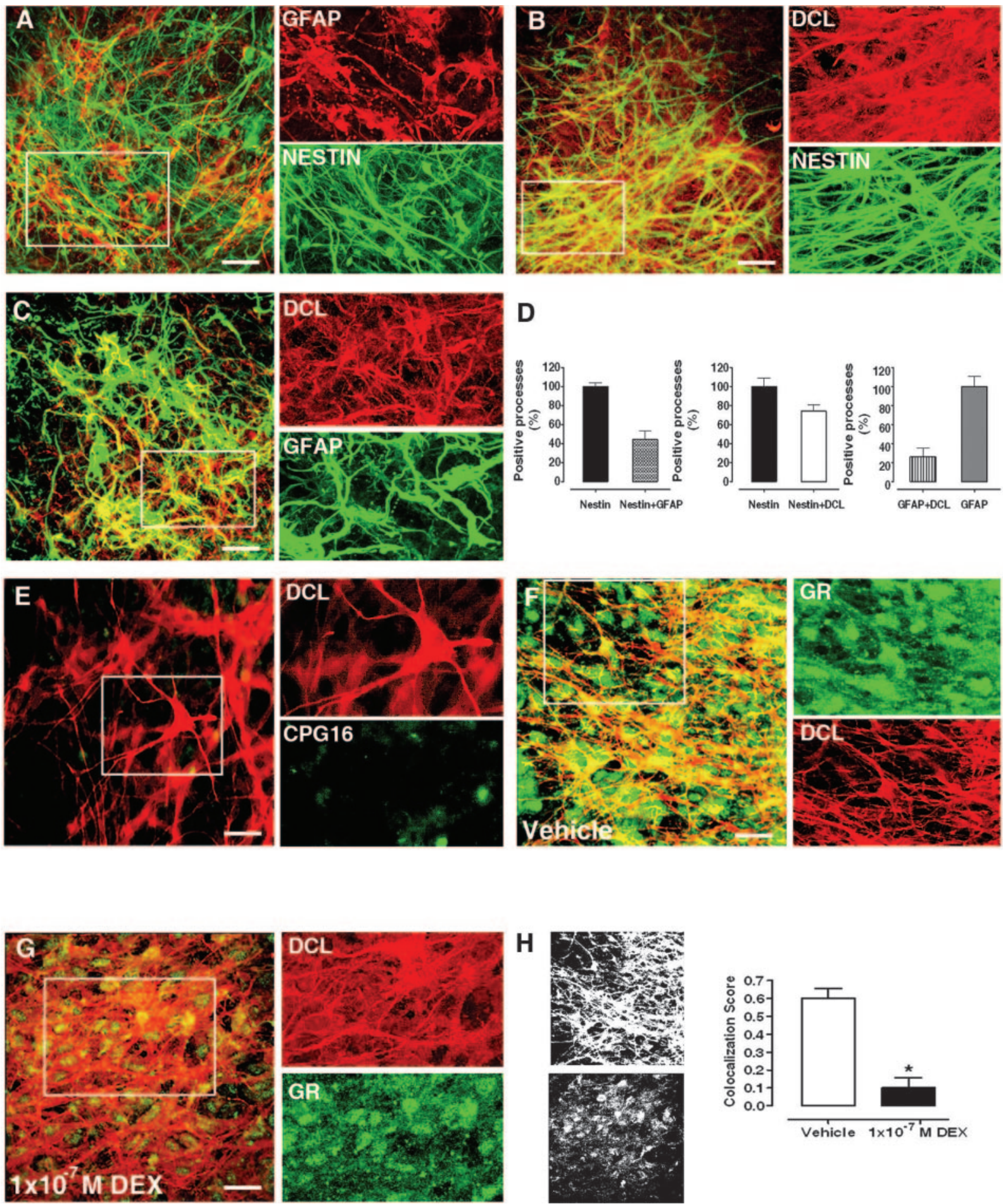

Fig. 8. Characterization of DCL-Expressing Cells in the Hilar Region of DIV5 Rat Hippocampal Organotypic Slice Cultures

A, Colocalization of GFAP (red) and nestin (green). B, Colocalization of DCL (red) and nestin (green). C, Colocalization of DCL $(r e d)$ and GFAP (green). D, Proportions of cellular processes positive for nestin, GFAP, and/or DCL. Cellular processes were selected as areas of interest for score calculations. E, Characterization of DCLK isoforms expressed. Inset, weak signal observed for kinase domain-containing isoforms (CPG16, green) and lack of colocalization to the DCL (red) in processes. F, Colocalization of GR (green) and DCL (red). Inset, distribution of GR in cellular processes in vehicle-treated slices. G, DEX-induced GR translocation. Inset, decrease in GR (green) localization in cellular processes (DCL, red) as compared with F. H, Grayscale bitmaps from panels $\mathrm{F}(t o p)$ and $\mathrm{G}$ (bottom) and the corresponding GR/DCL colocalization scores in cellular processes. ${ }^{*}, P<0.05$. Scale bars, $20 \mu \mathrm{m}$ in $\mathrm{A}, \mathrm{B}, \mathrm{C}, \mathrm{F}$, and $\mathrm{G}$; $32 \mu \mathrm{m}$ in $\mathrm{E}$. 
In line with recent reports describing the expression of GR in NPCs $(5,6)$, we found that the vast majority of DCL-positive NPCs were GR positive $(82.7 \pm 9.5 \%$ from a total of 278 cells counted in three independent OTSs; Fig. 6F). Incubation in culture medium containing DEX $\left(1 \times 10^{-7} \mathrm{M}, 90 \mathrm{~min}\right)$ induced a significant GR translocation from the cellular processes to the nuclear and perinuclear area in these cells (Fig. 8, F and $\mathrm{G})$, leading to a marked decrease in colocalization of GR to DCL in cellular processes (Fig. $8 \mathrm{H}$ ).

As a whole, our results in OTSs suggest that DCL is involved in GR translocation in NPCs.

\section{DISCUSSION}

In the present work, we have demonstrated that the MAP DCL is involved in GR translocation to the nucleus. Cytoplasmic GR is known to be part of large protein heterocomplexes containing hsp90, immunophilins, and motor proteins of the dynein family, which, upon ligand binding, transport activated GR to the nucleus using the microtubule cytoskeleton as a guiding scaffold (4). The data presented here show, for the first time, that a cell type-specific MAP, DCL, is an important regulator of this transport system that retrogradely conveys activated GR to the nucleus in NPCs.

The role of the cytoskeleton and the associated chaperone machinery designated transportosome in GR translocation to the nucleus has remained controversial $(26,27)$. Nevertheless, the hindrance induced by the cytoskeleton-disrupting drug colchicine on GR signaling is primarily attributable to perturbation of the microtubule network (28). In vivo, MAPs control microtubule dynamics in cellular processes in which microtubules act as tracks for cellular motors and to generate force (29). Furthermore, a new role for MAPs in regulating motor-based transport in neurons has been recently proposed (30). Based on our present data, we postulate that MAPs such as DCL are involved in GR transport and provide the actual cell type-specific control signals required for transport regulation.

In line with this concept, it has been suggested that hippocampal cells may have unique transporting mechanisms for accumulating GR in the nucleus (26), a notion that is supported by the role of DCL in GR translocation in NPCs. Indeed, differences in expression of MAPs and other cytoskeletal proteins in the hippocampus have suggested region-specific functions of the neuronal cytoskeleton (31).

Nevertheless, from the present set of data we cannot exclude the possibility that the observed effects on GR transport are a consequence of DCL down-regulation on other cellular processes, e.g. cell differentiation. In fact, our hypothesis that DCL is involved in GR retrograde transport accommodates such a possibility, given the well-described changes in expression of diverse components of the cytoskeleton that take place during neuronal differentiation, including isoforms of the DCLK gene $(7,25)$. Thus, although our observations altogether demonstrated a direct DCL-GR interaction, the precise mechanism by which DCL affects GR translocation remains to be fully characterized.

In our experiments DCL overexpression induced impairment of GR translocation to the nucleus, whereas overexpression of a C-terminal truncated DCL did not affect GR translocation. These observations point to an involvement of the serine/proline-rich C-terminal domain of DCL in interactions with the GR. Alternatively, taking into account c-Jun $\mathrm{N}$-terminal kinase (JNK)-mediated phosphorylation of DCX in its C-terminal domain (10) and JNK association with the GR (32), interactions with members of the JNK signaling cascade may be involved in DCL effects on GR translocation. Importantly, the C-terminal domain of DCX and the corresponding homology domain of DCLK have been linked through direct protein-protein interactions with protein transport or receptor recycling within migrating neurons $(18,33)$. In line with such a model, studies have shown that DCX binding to microtubules leaves its C-terminal domain accessible for interaction with other proteins (34). Based on the high homology between DCX and DCL (9), it is likely that similar features are present in DCL, but further experiments are required to accurately identify direct interaction partner(s).

DCL down-regulation resulted in a significant impairment of GR translocation to the nucleus along with retention of $\mathrm{GR}$ in neurites and a significant reduction in GR-dependent transcriptional activity in mouse neuroblastoma cells. This seemingly contradictory observation is in line with reports showing that both overexpression and down-regulation of DCLK have similar biological effects (8), suggesting that a proper stoichiometry is central to function of cytoskeleton regulators from the family of doublecortin domaincontaining MAPs (29). One possible explanation could be that overexpression of DCL generates protein accumulations on microtubules that may congest motor protein-dependent cargo movement as reported for other MAPs (30), whereas DCL knockdown depletes microtubules of a protein possibly involved in motor protein-dependent cargo movement.

Upon DCL down-regulation, mitochondria positioning was not affected, in line with observations showing that DCX does not block kinesin-dependent transport in neurons (29). Nevertheless, axonal transport of synaptic vesicles is severely compromised in DCX/DCLK knockout mice (11), indicating specific roles for proteins of this family in microtubule-based cargo transport. Moreover, DC-domain containing proteins have been linked to protein transport or receptor recycling within migrating neurons (18). Data presented herein provide, for the first time, evidence supporting such functions in NPCs.

In systems with endogenous expression, such as mouse neuroblastoma cells and NPCs, DCL is neces- 
sary for adequate translocation of activated GR to the nucleus. Comparable findings have been reported for GR transportosome-associated immunophilins (3). Additionally, we and others have identified the DCLK gene and components of the GR transportosome such as hsp90, dynein, and several immunophilins to be GC-responsive genes $(3,35,36)$. Accordingly, expression of different MAPs is altered by GC (37), and exposure to high GC levels induces marked downregulation of MAPs in the developing baboon (38) and sheep (39) brain. Thus, GR may control the expression of regulators of its intracellular transport (3). Differential regulation of the expression of components of the GR transportosome could add to a hitherto underestimated cell type-specific control of GR translocation. As we show that the amount of GR translocated to the nucleus directly influences GC-responsive elementdependent transcription, DCL may be involved in regulating GC actions, particularly in NPCs where activated GR controls cell proliferation and neurogenesis $(5,6)$.

Because neuronal differentiation of NPCs in the adult dentate gyrus mimics that of embryonic NPCs (40), our results may be of relevance for understanding the effects of stress and GC on adult neurogenesis as well. Suggestively, the DCLK gene has been recently implicated in neurogenesis and neuronal migration (8, 9 , 11). The molecular tools to manipulate DCL expression described herein open up the possibility to test $\mathrm{DCL}$ functions in physiologically relevant models of GC-regulated neurogenesis.

In conclusion, we report, for the first time, the involvement of the cell type-specific MAP DCL in the translocation of activated GR to the nucleus, which has important implications for the effects that circulating GC have on NPCs. The specific expression of DCL in NPCs (9) and its involvement in GR translocation suggest a specialized system by which NPCs react toward GC stimulation. The existence of a broader MAP-dependent, cell-specific control of GR translocation could help to explain cell type specificity of GC actions on neuronal cells, particularly concerning neurogenesis and adaptation to stress in the hippocampus. Our current efforts are directed to further characterize this mechanism.

\section{MATERIALS AND METHODS}

\section{Vectors, Antibodies, and Reagents}

YFP-GR was supplied by Dr. Cidlowski (National Institute of Environmental Health Sciences, National Institutes of Health); YFP-angiogenin was supplied by Dr. Xu (Zhejiang University School of Medicine, China). DCL-DsRed2 was generated by excising DCL cDNA from pcDNA 3.1-DCL (9) using Xhol/ $\mathrm{BamHI}$ and subcloning it into pDsRed2-N1 vector (Invitrogen BV). The DCL C-terminal truncation T285DCL-DsRed2 was generated from DCL-DsRed2 by PCR. EGFP-DCL was generated by excising DCL CDNA from pcDNA 3.1-DCL using $\mathrm{Xhol} / \mathrm{BamHI}$ and subcloning it into pEGFP-C1 vector (Invitro- gen BV). pSuper-DCL (pS-DCL) and its mismatched control pS-DCLm have been previously described (9). The modified lentiviral vectors LV-DCL-DsRed2, LV-DCL, and its mismatched control LV-DCLm were generated by subcloning the double-stranded DNA short hairpins present in pS-DCL and pS-DCLm into the lentiviral vector pLV-CMV-eGFP (41). EGFP was replaced by DCL-DsRed2 in LV-DCL-DsRed2. Lentivirus stocks were produced in 293FT cells using the ViraPower Lentiviral Expression System (Invitrogen BV) following manufacturer's instructions. Primary antibodies GR (M-20) rabbit polyclonal antibody, dynein intermediate chain mouse monoclonal antibody, and GFAP (2E1) mouse monoclonal antibody were from Santa Cruz Biotechnology, Inc. (Santa Cruz, CA); GR (BuGR2) mouse monoclonal antibody was from Abcam (Cambridgeshire, UK); DCLK (CaMKLK Sn370) rabbit polyclonal antibody has been previously described (9, 42); nestin mouse monoclonal antibody and CPG16/CaM kinase VI mouse polyclonal antibody were from BD Biosciences (Breda, The Netherlands), and $\alpha$-Tubulin (Clone DM 1A) mouse monoclonal antibody was from SigmaAldrich (Zwijndrecht, The Netherlands). Alexa Fluor488 or Alexa Fluor594-conjugated secondary antibodies were from Molecular Probes/Invitrogen (Breda, The Netherlands) and horseradish peroxidase-conjugated secondary antibody was from Santa Cruz Biotechnology, Inc. Dexamethasone (DEX), RU486 (Mifepristone), and 17-allylamino-17-demethoxygeldanamycin (17-AAG) were from Sigma-Aldrich. Paclitaxel (Taxol) was from Calbiochem/Merck Biosciences (UK). All tissue culture supplies and media were from Invitrogen BV.

\section{Cell Culture and Transfection}

African green monkey kidney COS-1 cells and mouse neuroblastoma N1E-115 cells were cultured and transfected as previously described $(9,43)$. Transfection efficiency, optimized with pEGFP-C1, was routinely found to be $75-80 \%$. N1E-115 cells were induced to differentiate into a neuronal phenotype by culture in DMEM, $100 \mathrm{U} / \mathrm{ml}$ penicillin, 100 $\mu \mathrm{g} / \mathrm{ml}$ streptomycin, and $2.5 \%$ fetal bovine serum in the presence of $2 \%$ DMSO for $5 \mathrm{~d}$ when, in our hands, neurite outgrowth was most strongly observed (20). Control cells were cultured in the same medium without the addition of DMSO. For all experiments involving GR translocation to the nucleus and GR-dependent transcriptional activity, cells were cultured in medium containing activated charcoalstripped fetal bovine serum $24 \mathrm{~h}$ before stimulation, as described (44).

Rat Hippocampal Organotypic Slice Cultures, Lentiviral Vector Transduction, and Pharmacological Treatments

Early postnatal rat hippocampal OTS cultures were prepared from 4- to 6-d-old male Wistar rats (Charles River Laboratories, Inc., Frankfurt, Germany) using the modified interface culture method (45). At the time of the first medium change (DIV1) hippocampal slices were inoculated with $10 \mu \mathrm{l}$ of the lentiviral vector stocks. Slices were fixed 4 d later with $4 \%$ paraformaldehyde for $1 \mathrm{~h}$ at $4 \mathrm{C}$ and used for immunofluorescence studies. For GR localization experiments, slices were cultured in medium containing activated charcoalstripped horse serum $24 \mathrm{~h}$ before stimulation and then incubated with DEX added to the culture medium to a final concentration of $1 \times 10^{-7} \mathrm{M}$ or vehicle (ethanol; maximum final concentration in medium, $0.001 \%$ ) for $90 \mathrm{~min}$ before fixation. All experiments were carried out with the approval of the Animal Care Committee of the Faculty of Medicine, Leiden, The Netherlands (DEC no. 06036).

\section{Real-Time Quantitative PCR}

RNA was purified using Trizol (Invitrogen BV), cDNA was synthesized using the iScript cDNA synthesis kit (Bio-Rad 
Laboratories, Veenendaal, The Netherlands), and real-time QPCR was performed using the Platinum SyBR Green QPCR kit (Invitrogen BV) on a LightCycler System (Roche Applied Science, Venlo, The Netherlands), as previously described (46).

\section{Protein Extraction and Western Blotting}

Protein extraction, SDS-PAGE, and Western blotting were performed as previously described (9). All blots were repeated at least three times, and one representative image is shown. Relative optical densities were analyzed using ImageJ software (NIH, Bethesda, MD) on images obtained from three independent blots.

\section{Immunoprecipitation Experiments}

Human cervical carcinoma (HeLa) cells were transfected using Superfect following manufacturer's instructions (QIAGEN Benelux B.V., Venlo, The Netherlands). Transfected cells were lysed as described above, and immunoprecipitation from the cell lysates and Western blot detection were done with the ExactaCruz $\mathrm{F}$ kit, following manufacturer's instructions (Santa Cruz Biotechnology). The GR antibody (H300, Santa Cruz Biotechnology) was used as immunoprecipitating antibody. Rabbit nonimmune IgG was used as negative control for the immunoprecipitation step (SC-2027, Santa Cruz Biotechnology). Both GR and DCL antibodies were used for Western blot detection.

\section{FRET Experiments}

All imaging experiments were performed on a Digital Eclipse C1si Spectral Laser Confocal System (Nikon, Badhoevedorp, The Netherlands) equipped with Diode, multiline Argon, and DPSS lasers (Melles Griot) attached to a TE2000E-PFS inverted microscope equipped with Perfect Focusing System (Nikon). Expression levels of donor (EGFP) and acceptor (EYFP) proteins were controlled by Western blot. Previous to FRET experiments, cotransfected cells were fixed as described above.

The EGFP-EYFP donor-acceptor pair was chosen based on its increased sensitivity for FRET $(47,48)$. Therefore, spectral imaging and linear unmixing for FRET analysis by sensitized emission were done essentially as described by Zimmermann et al. (49), with some modifications. Emission spectra of EGFP and EYFP were acquired from fixed cells expressing only one of the fluorescent fusion proteins with excitation wavelength of 457 and $488 \mathrm{~nm}$, previously used to excite EGFP as a FRET donor $(47,49)$. From these spectra (supplemental Fig. 2) and available spectra for EYFP (http:// probes.invitrogen.com/resources/spectraviewer), EGFP was excited by using the 457-nm and EYFP was excited by using the 514 Ar laser lines, respectively. Fluorescence emission was collected in spectral windows spanning from 470 to 500 and from 530 to $600 \mathrm{~nm}$ for EGFP and EYFP, respectively. Calibration of the FRET conditions was performed using an EYFP-EGFP fusion protein (47). Laser power and detector gain were adjusted in the different settings to observe similar concentrations of EGFP and EYFP, as calibrated by Western blot. Settings were kept unchanged for analysis of all samples. EGFP and EYFP spectral bleed-through in FRET settings were determined from cells expressing only EGFP-DCL or EYFP-GR by calculating intensity ratios in the appropriate settings (50) (IFRET/IDonor and IFRET/IAcceptor, respectively; supplemental Fig. 2).

FRET intensities were then corrected for spectral bleedthrough and normalized (NFRET) for expression levels (50).

\section{Reporter Gene Assays}

GR-dependent transcriptional activity was measured in transfected COS-1 cells and N1E-115 cells by using a Dual Luciferase (Promega Corp., Madison, WI)-based GC response element reporter gene assay as previously described (44). Cells were cotransfected with indicated constructs and $48 \mathrm{~h}$ after transfection, were treated overnight with DEX Results are expressed as mean GR transcriptional activity \pm SEM of three independent experiments performed in triplicate.

\section{Immunofluorescence and Laser-Scanning Confocal Microscopy}

Double/triple immunofluorescence and laser-scanning confocal microscopy in COS-1 cells, N1E-115 cells, and freefloating tissue slices was done as previously described (9). Analysis of intracellular localization was done with ImageJ and expressed as a nuclear/cytosolic intensity ratio guided by Hoechst 3342 stain as described previously (51). Expression of markers and localization were done counting at least 50 cells in the hilar region per slice. Fluorescent cell counting was performed using ImageJ. Quantification of EGFP/GR colocalization in processes of EGFP+ NPCs was done with ImageJ (JACoP plugin). Images were transformed to 8 bits, and a colocalization score representing the Overlap Coefficient R (52) was calculated. For experiments in N1E-115 cells, colocalization with tubulin was used.

\section{Curve Fitting and Statistical Analyses}

Dose-response and kinetic curve fitting and data analysis were carried out by nonlinear regression using Prism 4.0 and statistical analyses with InStat 3.0 (GraphPad Software, Inc., San Diego, CA). For dose-response curves, a sigmoidal dose-response equation $[Y=$ Bottom + (Top -Bottom $) /(1+$ $10^{\prime}\left(\operatorname{LogEC}_{50}-\mathrm{X}\right)$ ] was used, from which $\mathrm{EC}_{50}$ and maximal effects were estimated. For kinetic curves a one-phase exponential association equation $\left[Y=Y_{\max }{ }^{*}\left(1-\exp \left(-\mathrm{K}^{*} \mathrm{X}\right)\right)\right]$ was used, from which half-times and $Y_{\max }$ were estimated. Unpaired $t$ test (two groups) or one-way ANOVA test (three or more groups) was applied as previously described (53) and a $P$ value $<0.05$ was considered significant in all cases.

More detailed descriptions of the materials and methods used in this study are provided as supplemental data.

\section{Acknowledgments}

We thank Dr. S. Le Dévédec for technical advice and Dr. N. Datson for revisions on the English language. C.P.F. acknowledges Dr. S. A. Fratantoni for critical revisions on the manuscript.

Received May 7, 2007. Accepted October 23, 2007.

Address all correspondence and requests for reprints to: Erno Vreugdenhil, Leiden/Amsterdam Center for Drug Research/Medical Pharmacology Department, Einsteinweg 55, P.O. Box 9502, 2300 RA Leiden, The Netherlands. E-mail: vreugden@lacdr.leidenuniv.nl.

This research was supported by grants from The Netherlands Technology Foundation (S.T.W.), the Applied Science Division of The Netherlands Scientific Organization, the Technology Program of The Netherlands Ministry of Economic affairs (LFA6332), and The Center for Medical System Biology, Leiden, The Netherlands (to E.V.) The Multiphoton and Laser-Scanning Confocal Microscopy Facility at the Leiden/ Amsterdam Center for Drug Research/Leiden University is supported by The Netherlands Scientific Organization Grant 911-02-022. 
Disclosure Summary: The authors have nothing to disclose.

\section{REFERENCES}

1. de Kloet ER, Joels M, Holsboer F 2005 Stress and the brain: from adaptation to disease. Nat Rev Neurosci 6:463-475

2. Picard D, Khursheed B, Garabedian MJ, Fortin MG, Lindquist S, Yamamoto KR 1990 Reduced levels of hsp90 compromise steroid receptor action in vivo. Nature 348:166-168

3. Wochnik GM, Ruegg J, Abel GA, Schmidt U, Holsboer F, Rein T 2005 FK506-binding proteins 51 and 52 differentially regulate dynein interaction and nuclear translocation of the glucocorticoid receptor in mammalian cells. J Biol Chem 280:4609-4616

4. Pratt WB, Galigniana MD, Harrell JM, DeFranco DB 2004 Role of hsp90 and the hsp90-binding immunophilins in signalling protein movement. Cell Signal 16:857-872

5. Garcia A, Steiner B, Kronenberg G, Bick-Sander A, Kempermann G 2004 Age-dependent expression of glucocorticoid- and mineralocorticoid receptors on neural precursor cell populations in the adult murine hippocampus. Aging Cell 3:363-371

6. Sundberg M, Savola S, Hienola A, Korhonen L, Lindholm D 2006 Glucocorticoid hormones decrease proliferation of embryonic neural stem cells through ubiquitin-mediated degradation of cyclin D1. J Neurosci 26:5402-5410

7. Burgess HA, Reiner O 2002 Alternative splice variants of doublecortin-like kinase are differentially expressed and have different kinase activities. J Biol Chem 277: 17696-17705

8. Shu T, Tseng HC, Sapir T, Stern P, Zhou Y, Sanada K, Fischer A, Coquelle FM, Reiner O, Tsai LH 2006 Doublecortin-like kinase controls neurogenesis by regulating mitotic spindles and $\mathrm{M}$ phase progression. Neuron 49: 25-39

9. Vreugdenhil E, Kolk SM, Boekhoorn K, Fitzsimons CP, Schaaf M, Schouten TG, Angela Sarabdjitsingh A, Sibug R, Lucassen PJ 2007 Doublecortin-like, a microtubule associated protein expressed in radial glia is crucial for neuronal precursor division and radial process stability. Eur J Neurosci 25:635-648

10. Deuel TA, Liu JS, Corbo JC, Yoo SY, Rorke-Adams LB, Walsh CA 2006 Genetic interactions between doublecortin and doublecortin-like kinase in neuronal migration and axon outgrowth. Neuron 49:41-53

11. Gdalyahu A, Ghosh I, Levy T, Sapir T, Sapoznik S, Fishler Y, Azoulai D, Reiner O 2004 DCX a new mediator of the JNK pathway. EMBO J 23:823-832

12. Harrell JM, Murphy PJ, Morishima Y, Chen H, Mansfield JF, Galigniana MD, Pratt WB 2004 Evidence for glucocorticoid receptor transport on microtubules by dynein. J Biol Chem 279:54647-54654

13. Schaaf MJ, Cidlowski JA 2003 Molecular determinants of glucocorticoid receptor mobility in living cells: the importance of ligand affinity. Mol Cell Biol 23:1922-1934

14. Galigniana MD, Scruggs JL, Herrington J, Welsh MJ, Carter-Su C, Housley PR, Pratt WB 1998 Heat shock protein 90-dependent (geldanamycin-inhibited) movement of the glucocorticoid receptor through the cytoplasm to the nucleus requires intact cytoskeleton. Mol Endocrinol 12:1903-1913

15. Usuku T, Nishi M, Morimoto M, Brewer JA, Muglia LJ, Sugimoto T, Kawata M 2005 Visualization of glucocorticoid receptor in the brain of green fluorescent proteinglucocorticoid receptor knockin mice. Neuroscience 135:1119-1128

16. Garside H, Stevens A, Farrow S, Normand C, Houle B, Berry A, Maschera B, Ray D 2004 Glucocorticoid ligands specify different interactions with NF- $\kappa \mathrm{B}$ by allosteric effects on the glucocorticoid receptor DNA binding domain. J Biol Chem 279:50050-50059

17. Galigniana MD, Harrell JM, Housley PR, Patterson C, Fisher SK, Pratt WB 2004 Retrograde transport of the glucocorticoid receptor in neurites requires dynamic assembly of complexes with the protein chaperone hsp90 and is linked to the CHIP component of the machinery for proteasomal degradation. Brain Res Mol Brain Res 123: 27-36

18. Friocourt G, Chafey P, Billuart P, Koulakoff A, Vinet MC, Schaar BT, McConnell SK, Francis F, Chelly J 2001 Doublecortin interacts with $\mu$ subunits of clathrin adaptor complexes in the developing nervous system. Mol Cell Neurosci 18:307-319

19. Schwarz PM, Gierten B, Boissel JP, Forstermann U 1998 Expressional down-regulation of neuronal-type nitric oxide synthase I by glucocorticoids in N1E-115 neuroblastoma cells. Mol Pharmacol 54:258-263

20. Kobayashi M, Taniura H, Yoshikawa K 2002 Ectopic expression of necdin induces differentiation of mouse neuroblastoma cells. J Biol Chem 277:42128-42135

21. Mandelkow EM, Thies E, Trinczek B, Biernat J, Mandelkow E 2004 MARK/PAR1 kinase is a regulator of microtubule-dependent transport in axons. J Cell Biol 167:99-110

22. Namba T, Mochizuki H, Onodera M, Mizuno Y, Namiki H, Seki T 2005 The fate of neural progenitor cells expressing astrocytic and radial glial markers in the postnatal rat dentate gyrus. Eur J Neurosci 8:1928-1941

23. Kempermann G, Jessberger S, Steiner B, Kronenberg G 2004 Milestones of neuronal development in the adult hippocampus. Trends Neurosci 27:447-452

24. Engels BM, Schouten TG, van Dullemen J, Gosens I, Vreugdenhil E 2004 Functional differences between two DCLK splice variants. Brain Res Mol Brain Res 120: 103-114

25. Vreugdenhil E, Engels B, Middelburg R, van Koningsbruggen S, Knol J, Veldhuisen B, de Kloet ER 2001 Multiple transcripts generated by the DCAMKL gene are expressed in the rat hippocampus. Brain Res Mol Brain Res 94:67-74

26. Nishi M, Kawata M 2006 Brain corticosteroid receptor dynamics and trafficking: implications from live cell imaging. Neuroscientist 12:119-133

27. Picard D 2006 Chaperoning steroid hormone action. Trends Endocrinol Metab 17:229-235

28. Dvorak Z, Maurel P, Vilarem MJ, Ulrichova J, Modriansky M 2007 Expression and transcriptional activities of nuclear receptors involved in regulation of drug-metabolizing enzymes are not altered by colchicine: focus on PXR $\mathrm{CAR}$ and GR in primary human hepatocytes. Cell Biol Toxicol 23:63-73

29. Moores CA Perderiset M, Kappeler C, Kain S, Drummond D, Perkins SJ, Chelly J, Cross R, Houdusse A, Francis F 2006 Distinct roles of doublecortin modulating the microtubule cytoskeleton. EMBO J 25:4448-4457

30. Baas PW, Qiang L 2005 Neuronal microtubules: when the MAP is the roadblock. Trends Cell Biol 15:183-187

31. Arnold SE, Trojanowski JQ 1996 Human fetal hippocampal development. II. The neuronal cytoskeleton. J Comp Neurol 367:293-307

32. Bruna A, Nicolas M, Munoz A, Kyriakis JM, Caelles C 2003 Glucocorticoid receptor-JNK interaction mediates inhibition of the JNK pathway by glucocorticoids. EMBO J 22:6035-6044

33. Tsukada M, Prokscha A, Oldekamp J, Eichele G 2003 Identification of neurabin II as a novel doublecortin interacting protein. Mech Dev 120:1033-1043

34. Moores CA, Perderiset M, Francis F, Chelly J, Houdusse A, Milligan RA 2004 Mechanism of microtubule stabilization by doublecortin. Mol Cell 14:833-839 
35. Datson NA, van der Perk J, de Kloet ER, Vreugdenhil E 2001 Identification of corticosteroid-responsive genes in rat hippocampus using serial analysis of gene expression. Eur J Neurosci 14:675-689

36. Alfonso J, Aguero F, Sanchez DO, Flugge G, Fuchs E, Frasch AC, Pollevick GD 2004 Gene expression analysis in the hippocampal formation of tree shrews chronically treated with cortisol. J Neurosci Res 78:702-710

37. Bianchi M, Hagan JJ, Heidbreder CA 2005 Neuronal plasticity stress and depression: involvement of the cytoskeletal microtubular system? Curr Drug Targets CNS Neurol Disord 4:597-611

38. Antonow-Schlorke I, Schwab M, Li C, Nathanielsz PW 2003 Glucocorticoid exposure at the dose used clinically alters cytoskeletal proteins and presynaptic terminals in the fetal baboon brain. J Physiol 547:117-123

39. Schwab M, Antonow-Schlorke I, Kuhn B, Muller T, Schubert H, Walter B, Sliwka U, Nathanielsz PW 2001 Effect of antenatal betamethasone treatment on microtubule-associated proteins MAP1B and MAP2 in fetal sheep. J Physiol 530:497-506

40. Esposito MS, Piatti VC, Laplagne DA, Morgenstern NA, Ferrari CC, Pitossi FJ, Schinder AF 2005 Neuronal differentiation in the adult hippocampus recapitulates embryonic development. J Neurosci 25:10074-10086

41. Vellinga J, Uil TG, de Vrij J, Rabelink MJ, Lindholm L, Hoeben RC 2006 A system for efficient generation of adenovirus protein IX-producing helper cell lines. J Gene Med 8:147-154

42. Kruidering M, Schouten T, Evan GI, Vreugdenhil E 2001 Caspase-mediated cleavage of the $\mathrm{Ca} 2+/$ calmodulindependent protein kinase-like kinase facilitates neuronal apoptosis. J Biol Chem 276:38417-38425

43. Chong KW, Lee AY, Koay ES, Seet SJ, Cheung NS 2006 $\mathrm{pH}$ dependent high transfection efficiency of mouse neuroblastomas using TransFectin. J Neurosci Methods 158: 56-63

44. Meijer OC, Kalkhoven E, van der Laan S, Steenbergen PJ, Houtman SH, Dijkmans TF, Pearce D, de Kloet ER 2005 Steroid receptor coactivator-1 splice variants dif- ferentially affect corticosteroid receptor signaling. Endocrinology 146:1438-1448

45. Stoppini L, Buchs PA, Muller D 1991 A simple method for organotypic cultures of nervous tissue. J Neurosci Methods $37: 173-182$

46. Morsink MC, Steenbergen PJ, Vos JB, Karst H, Joels M, De Kloet ER, Datson NA 2006 Acute activation of hippocampal glucocorticoid receptors results in different waves of gene expression throughout time. J Neuroendocrinol 18:239-252

47. Harpur AG, Wouters FS, Bastiaens PI 2001 Imaging FRET between spectrally similar GFP molecules in single cells. Nat Biotechnol 19:167-169

48. Ganesan S, Ameer-Beg SM, Ng TT, Vojnovic B, Wouters FS 2006 A dark yellow fluorescent protein (YFP)-based resonance energy-accepting chromoprotein (REACh) for Forster resonance energy transfer with GFP. Proc Natl Acad Sci USA 103:4089-4094

49. Zimmermann T, Rietdorf J, Girod A, Georget V, Pepperkok R 2002 Spectral imaging and linear un-mixing enables improved FRET efficiency with a novel GFP2YFP FRET pair. FEBS Lett 531:245-249

50. Feige JN, Sage D, Wahli W, Desvergne B, Gelman L 2005 PixFRET, an Image $J$ plug-in for FRET calculation that can accommodate variations in spectral bleed-throughs. Microsc Res Tech 68:51-58

51. van der Laan S, Lachize SB, Schouten TG, Vreugdenhi E, de Kloet ER, Meijer OC 2005 Neuroanatomical distribution and colocalisation of nuclear receptor corepressor (N-CoR) and silencing mediator of retinoid and thyroid receptors (SMRT) in rat brain. Brain Res 1059: 113-121

52. Manders EMM, Verbeek FJ, Aten JA 1993 Measurement of co-localization of objects in dual-colour confocal images. J Microsc 69:375-382

53. Fitzsimons CP, Monczor F, Fernandez N, Shayo C, Davio C 2004 Mepyramine, a histamine H1 receptor inverse agonist, binds preferentially to a $\mathrm{G}$ protein-coupled form of the receptor and sequesters $\mathrm{G}$ protein. J Biol Chem 279:34431-34439

\section{Molecular Endocrinology is published monthly by The Endocrine Society (http://www.endo-society.org), the foremost} professional society serving the endocrine community. 